\title{
22
}

\section{Bio querbeet: vom Knochen zum Kern (Buchstaben-Anzahl)}

Trage die passenden Begriffe zu den folgenden acht Definitionen in das Raster ein. Die Buchstabenanzahl eines gefundenen Begriffs verrät dir, welcher Lösungsbuchstabe unten einzutragen ist (siehe Buchstabenschlüssel). Zum Beispiel „Ulna“: 4 Buchstaben, ergibt also ein $\mathrm{H}$.

\section{Definitionen}

(a) Organismus, der auf Kosten anderer lebt, (b) Elle (lat.), (c) Monosaccharid mit sechs Kohlenstoffatomen, (d) sessiles Stadium der meisten Cnidaria, (e) elektrisch geladenes Teilchen, (f) Kernkörperchen (lat.), (g) Abkürzung für Desoxyribonucleinsäure, (h) im Süßwasser lebend

\section{Buchstaben-Schlüssel}

3 Buchstaben $=\mathbf{O}, 4$ Buchstaben $=\mathbf{H}, 5$ Buchstaben $=\mathbf{G}$

6 Buchstaben $=\mathbf{A}, 7$ Buchstaben $=\mathbf{P}, 8$ Buchstaben $=\mathbf{M}, 9$ Buchstaben $=\mathbf{S}$

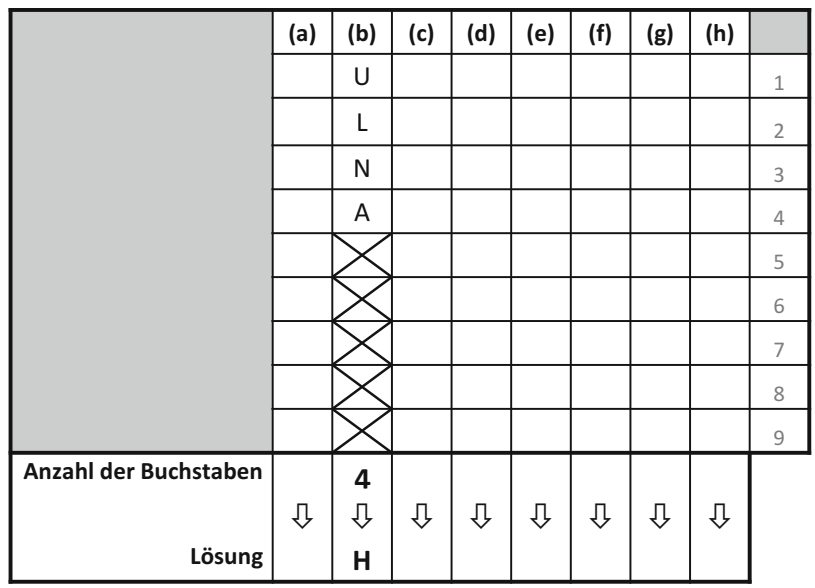

